\title{
Ebelik Öğrencilerinin Kültürrlerarası Yaklaşımlarının Merhamet ve Empati Düzeylerine Etkisi
}

\author{
DOI: $10.26466 /$ opus.591200
}

\begin{abstract}
*
Gülbahtiyar Demirel $^{*}$ - Nurdan Kaya ${ }^{* *}$ - Adem Doğaner ${ }^{* * *}$

* Doç. Dr., Sivas Cumhuriyet Üniversitesi, Sağlık Bilimleri Fakültesi, Sivas / Türkiye E-Posta: gulbahtiyar doganer@hotmail.com ORCID: 0000-0003-2258-7757

** Öğr. Gör., Sivas Cumhuriyet Üniversitesi, Suşehri Sağlık Yüksekokulu, Suşehri / Sivas / Türkiye E-Posta: nrdn.kaya@windowslive.com ORCID: 0000-0002-8910-381X

*** 3 Dr. Öğr. Üy., Kahramanmaraş Sütçü İmam Üniversitesi, Tıp Fakültesi, Kahramanmaraş/Türkiye E-Posta: adem doganer@hotmail.com ORCID: 0000-0002-0270-9350

\section{Öz}

Bu araştırma, ebelik öğrencilerinin kültürlerarası yaklaşımlarının empati ve merhamet düzeylerine etkisini belirlemek amacıyla yapılmıştır. Araştırma, tanımlayıcı araştırma özelliğindedir. Araştırmanın örneklemini, İç Anadolu bölgesinde yer alan bir üniversitesinin ebelik bölümünde öğrenim gören birinci ve dördüncü sınıf ebelik öğrencileri (147 kişi) oluşturmuştur. Araştırmanın verileri "Öğrenci Tanıtım Formu", "Kültürlerarası Duyarlllık Ölçeğgi", "Temel Empati Ölçeği" ve "Merhamet Ölçeği" ile toplanmıştır. Istatistiksel değerlendirmede ortalama, standart sapma, yüzdelik dağılım, Fisher Exact testi, Ki Kare testi, Mann-Whitney U testi ve Spearman Korelasyon testi kullanılmıştır. Araştırmadan elde edilen verilere göre, birinci ve dördüncü sını öğrencilerinin kültürlerarası duyarlllı, empati ve merhamet düzeyleri arasında istatistiksel açıdan anlamlı bir farklılık bulunmaktadır ( $p<0.05)$. Birinci sını öğrencilerinin kültürlerarası duyarlılı, merhamet ve bilişsel empati düzeyleri dördüncü sını öğrencilerinden daha fazladır ( $p<0.05)$. Birinci ve dördüncü sinı öğrencilerinin kültürlerarası duyarlılıkları ile merhamet düzeyleri arasında pozitif yönde, dördüncü sinıföğrencilerinin kültürlerarası duyarlılıkları ile temel empati düzeyleri arasında negatif yönde anlamlı düzeyde bir ilişki saptanmıştır ( $p<0.05)$. Elde edilen bulgular doğrultusunda; ebelik öğrencilerinin kültürlerarası yaklaşımlarının merhamet düzeyleri üzerine etkisi olduğu sonucuna varılabilir.
\end{abstract}

Anahtar Kelimeler: Ebelik, Empati, Merhamet, Kültürlerarası yaklaşım,Öğrenci 


\title{
The Effect of Intercultural Approaches of Midwifery Students on the Level of Compassion and Empathy
}

\begin{abstract}
This research was conducted to determine the effect of intercultural approaches of midwifery students on their empathy and compassion levels. The research was descriptively carried out. The sample of the research composed of freshmen and senior midwifery students (147 people) studying in the midwifery departments of a university in the Central Anatolia region. The data of research were collected by the "Student Description Form", "Intercultural Sensitivity Scale", "Basic Empathy Scale" and "Compassion Scale". The mean, standard deviation, percentage distribution, Fisher Exact test, Chi square test, Mann-Whitney $U$ test and Spearman correlation test were used for statistical evaluation. There was a statistically significant difference between the levels of intercultural sensitivity, empathy and compassion of the freshmen and senior students ( $p<0.05)$. The level of intercultural sensitivity, compassion and cognitive empathy of frehmen students was higher than that of senior students ( $p<0.05)$. There was a significant positive correlation between intercultural sensitivity and compassion levels of the freshmen and senior students, and a negative correlation between the intercultural sensitivity and the basic empathy levels of the senior students $(p<0.05)$. As a result of the findings, it can be concluded that the intercultural approaches of midwifery students have an effect on the levels of compassion.
\end{abstract}

Keywords: Midwifery, Empathy, Compassion, Intercultural approach, Student 


\section{Giriş}

Kültür, insan yaşamından ayrı düşünülmeyen, doğumdan ölüme kadar bireyi birçok boyutta etkileyen, öğrenilen, paylaşılan, nesilden nesile aktarılan değerler, inançlar, tutum ve davranışlar, örf ve adetleri kapsayan dinamik bir yapıdır (Bulduk, Usta ve Dinçer 2017; Ceylantekin ve Öcalan, 2016). İnsanların bireysel ve sosyal değerlerini, kişisel inançlarını ve sağlık uygulamalarını kültür etkilemektedir. İnsanların sağlıkla ilgili inanç ve uygulamaları, içinde yaşadığı toplumun kültürünün bir parçasıdır. Topluma verilen sağlık hizmetleri, bakım verilen grubun hastalık ve sağllğ 1 nasıl algıladıkları ve hastalık, sağlığa nasıl tepki verdiklerinden etkilenmektedir. Toplumun sağlıkla ilgili davranışlarını geliştirebilmek için sağlık çalışanlarının bu tür davranışların arkasında hangi kültürel etmenlerin yer aldığını bilmesi önemlidir (Tortumluoğlu, 2004).

Değişen dünyamızla birlikte sağlık bakım hizmetlerinde, kültürel farkındalık ve duyarlılık kavramları ortaya çıkmış ve bakım sunumunda önemi vurgulanmaya başlanmıştır (Bulduk vd. 2017; Ceylantekin ve Öcalan, 2016; Cetişli vd. 2016; Aktaş, Uğur ve Orak, 2016; Tanrıverdi, 2017). Kültürlerarası duyarlılık; "kültürlerarası farklılıkları anlamada, kabul etmede ve takdir etmede kendi motivasyonunu sağlamak için gerekli olan aktif istek" olarak tanımlanmaktadır (Bulduk, Tosun ve Ardıç, 2011). Yapılan çalışmalar sağlık çalışan ve öğrencilerinin kültürel farkındalık ve duyarlılıklarının hastaya verilen hizmeti etkilediğini ortaya koymaktadır (Bulduk vd. 2017; Ceylantekin ve Öcalan, 2016; Aktaş vd. 2016; Valizadeh, Zamanzadeh, Ghahramanian ve Aghajari, 2017).

Kültürlerarası duyarlılı̆̆ın merkezi unsurlarından birisi empatidir (Chen ve Starosta, 2000). Empati; kişinin kendini, karşıdaki kişinin yerine koyarak, onun duygu ve düşüncelerini anlamasıdır (Deane-Gray, 2004). Hemşirelik öğrencileri ile yapılan bir çalışmada öğrencilerin empati düzeylerinin artması ile kültürlerarası duyarlılıklarının arttı̆̆ı saptanmıştır (Çetişli vd. 2016). Sağlık bakımı esnasında empati yoluyla gösterilen merhamet ise bakımı kolaylaştırmakta ve kalitesini artırmaktadır (Polat ve Erdem, 2017).

Merhamet sağlık bakım hizmeti sunanlar için önemli bir değerdir. Hemşireliğin öncülerinden Rahibe Simone Roach'a göre profesyonel bakımın beş önemli özelliği şefkat, yetkinlik, güven, taahhüt ve vicdandır 
(Dinç, 2010). Merhamet ve şefkat kavramları aynı anlamda kullanılabilmektedir (Uslu ve Buldukoğlu, 2017). Yapılan bir çalışmada hemşirelerin, kültürlerarası duyarlılıkları ve merhamet düzeyleri arasında anlamlı derecede pozitif yönde bir ilişki olduğu bulunmuştur (Arli ve Bakan, 2018).

Sağlık bakım hizmetlerinin sunumunda önemli rol ve sorumluluğa sahip profesyonel mesleklerden birisi, ebeliktir. Ebelik uygulamalarının odağında, kadın sağlığı, üreme sağlığı, perinatal sağlık, yenidoğan ve çocuk sağ lığı, aile sağlığı ve toplum sağllğının geliştirilmesi, korunması ve sürdürülmesi yer almaktadır. Tüm bu alanlar kültürel özelliklerden yoğun olarak etkilenmektedir. Ebelerin, kültürlerarası duyarlılığa sahip olması, merhamet ve empatik yaklaşımları bakımının kalitesini etkileyebilmektedir (Ménage, Bailey, Lees ve Coad, 2017). Bu bakımdan geleceğin ebeleri olacak ebelik öğrencilerinin, kültürlerarası yaklaşımlarının belirlenmesi önemlidir. Literatürde ebelik öğrencilerinin kültürlerarası yaklaşımlarının empati ve merhamet üzerinde nasıl bir etkisi olduğunu araştıran çalışmaya rastlanmamıştır. Bu nedenle araştırma ebelik öğrencilerinin kültürlerarası yaklaşımlarının belirlenmesi, kültürlerarası yaklaşımlarının empati ve merhamet düzeylerine etkisini belirlemek amacıyla yapılmiştır.

\section{Yöntem}

Bu çalışma tanımlayıcı araştırma tipinde olup, Sivas Cumhuriyet Üniversitesi Sağlık Bilimleri Fakültesi Ebelik Bölümünde yapılmıştır. Araştırmanın evrenini 2017-2018 eğitim-öğretim dönemi bahar yarıyılında Sivas Cumhuriyet Üniversitesi Sağlık Bilimleri Fakültesi Ebelik Bölümünde okuyan birinci ( 85 kişi) ve dördüncü (73 kişi) sınıf ebelik öğrencileri oluşturmuştur. Araştırmanın örnekleminde ise 2017-2018 eğitim-öğretim dönemi bahar yarıyılında öğrenim gören, araştırmaya katılmaya gönüllü birinci (78 kişi) ve dördüncü (69 kişi) sınıf ebelik öğrencileri yer almıştır.

Araştırmanın verileri araştırmacılar tarafından literatür bilgisi doğrultusunda oluşturulan "Öğrenci Tanıtım Formu”, "Kültürlerarası Duyarlılık Ölçeğii", "Temel Empati Ölçeği” ve "Merhamet Ölçeği” ile toplanmıştır. 
Öğrenci Tanıtım Formu: Anket formunda öğrencinin yaş, cinsiyet, öğrenim bilgilerini, ebelik eğitimi ve kültüre ilişkin bilgilerini belirlemeye yönelik 10 soru yer almaktadır.

Kültürlerarası Duyarlılık Ölçeği: Kültürlerarası Duyarlılık Ölçeği (KDÖ) Chen ve Starosta (2000) tarafından geliştirilmiş olup ülkemiz için Türkçe geçerlik ve güvenirlik çalışması Bulduk vd. (2011) tarafından yapılmıştır. Ölçek toplamda 24 madde ve beş boyuttan oluşmaktadır. Ölçeğin İletişimde Sorumluluk Boyutu yedi maddeden (1, 11, 13, 21, 22, 23 ve 24. madde), Kültürel Farklılıklara Saygı Boyutu altı maddeden $(2,7,8,16,18$ ve 20. madde), İletişimde Kendine Güvenme Boyutu beş maddeden (3, 4, 5, 6 ve 10. madde), İletişimden Hoşlanma Boyutu üç maddeden $(9,12$ ve 15. Madde) ve İletişimde Dikkatli Olma Boyutu üç maddeden (14, 17 ve 19. Madde) oluşmaktadır. Ölçeğin 2, 4, 7, 9, 12, 15, 18, 20 ve 22. maddeleri ters olarak kodlanmaktadır. Ölçek (1) kesinlikle katılmıyorum, (2) katılmıyorum, (3) kararsızım, (4) katılıyorum ve (5) kesinlikle katılıyorum şeklinde 5'li likert tipi bir derecelendirmeye sahiptir. Ölçekten alınabilecek en düşük toplam puan 24, en yüksek toplam puan 120'dir. Ölçekten alınan toplam puanın artması kültürlerarası duyarlılık düzeyinin arttığını göstermektedir. Bulduk vd. (2011) tarafından Türkçe Kültürlerarası Duyarl1lık Ölçeği'nin Cronbach Alpha katsayısı .72 (yeterli) olarak hesaplanmıştır. Bu çalışmada ölçeğin Cronbach Alpha değerinin 0.73 olduğu tespit edilmiştir.

Temel Empati Ölçeği (TEÖ): Temel Empati Ölçeği (TEÖ) Jolliffe ve Farrington (2006) tarafından geliştirilmiş olup, ülkemiz için Türkçe geçerlik ve güvenirlik çalışması Topçu, Beker ve Aydın (2010) tarafından yapılmıştır. Ölçek toplamda 20 madde ve iki alt boyuttan oluşmaktadır. Ölçeğin bilişsel empati alt boyutu ölçen 9 maddesi $(3,6,9,10,12,14,16,19$ ve 20 . Maddeler) ve duygusal empati alt boyutu ölçen 11 maddesi $(1,2,4$, 5, 7, 8, $11,13,15,17,18$. maddeler) vardır. Ölçek 5'li likert tipi (1= Kesinlikle Katılmiyorum, 2= Katılmiyorum, 3=Ne Katıliyorum, Ne Katılmıyorum, 4= Katıllyorum, 5= Kesinlikle Katıllyorum) derecelendirmeye sahiptir. Ölçekte ters puanlanmış madde bulunmamaktadır. Ölçekten alınabilecek en düşük ve en yüksek puanlar sırasıyla, ölçeğin toplam puanı için 20-100, bilişsel empati alt boyutu için 9-45 ve duygusal empati alt boyutu için 11- 
55'tir. Ölçekten alınacak yüksek puanlar empati düzeyinin yüksek olduğunu, düşük puanlar ise empati düzeyinin düşük olduğunu göstermektedir. Topçu vd. (2010) tarafından yapılan geçerlilik ve güvenirlik çalışmasında ölçeğin Cronbach Alpha katsayısı .76-.80 aralığında ve yeterli bulunmuştur. Bu çalışmada ölçeğin Cronbach Alpha değerinin 0.83 olduğu tespit edilmiştir.

Merhamet Ölçeği: Merhamet Ölçeği (MÖ) Pommier (2011) tarafından geliştirilmiş olup, ülkemiz için Türkçe geçerlik ve güvenirlik çalışması Akdeniz ve Deniz (2016) tarafından yapılmıştır. Ölçek toplamda 24 madde ve altı alt boyuttan oluşmaktadır. Ölçeğin sevecenlik, umursamazlık, paylaşımların bilincinde olma, bağlantısızlık, bilinçli farkındalık ve ilişki kesme olmak üzere altı alt boyutu vardır. Ölçeğin sevecenlik alt boyutu 6, 8,16 ve 24 . maddeden, umursamazlık alt boyutu $2,12,14$ ve 18 . maddeden (tersten puanlama), paylaşımların bilincinde olma alt boyutu 11, 15, 17 ve 20. maddeden, bağlantısızlık alt boyutu 3, 5, 10 ve 22. maddeden (tersten puanlama), bilinçli farkındalık alt boyutu 4, 9, 13 ve 21 . maddeden, ilişki kesme alt boyutu 1, 7, 19 ve 23. maddeden (tersten puanlama) oluşmaktadır. Toplam Merhamet puanı için tersten puanlama yapılan alt boyutları puanladıktan sonra tüm alt boyutların toplamı alınmaktadır. Alt boyutları ayrı ayrı puanlama gerektiği durumlarda tersten puanlama yapılmamaktadır. Ölçek 5'li likert tipi (1= Hiçbir Zaman, 2= Nadiren, 3= Ara sıra, , 4= Sık Sık, 5= Her Zaman) derecelendirmeye sahiptir. Ölçekten alınan toplam puan arttıkça merhamet düzeyi de artmaktadır. Akdeniz ve Deniz'in (2016) çalışmasında ölçeğin Cronbach Alpha değeri 0.85 olarak bulunmuştur. Bu çalışmada ölçeğin Cronbach Alpha değerinin 0.86 olduğu tespit edilmiştir.

Araştırmaya başlamadan önce Sivas Cumhuriyet Üniversitesi Sağlık Bilimleri Fakültesi'nden ve Sivas Cumhuriyet Üniversitesi Girişimsel Olmayan Klinik Araştırmalar Etik Kurulu'ndan yazılı izin (2018-01/27) alınmıştır. Çalışmaya katılmaya gönüllü olan öğrencilere araştırmanın amacı ve içeriği hakkında bilgi verilmiş ve katılımları için yazılı onamları alınmıştır. Verilerin doğru olarak elde edilebilmesi için onam formu hariç diğer veri toplama formunda isim belirtmenin zorunlu olmadığı, her türlü bilginin gizli kalacağı açıklanmıştır. Verilerin sadece araştırma kapsamında kullanılacağı, gizliliğin kesinlikle sağlanacağı belirtilmiştir. 
Araştırmaya katılmaya gönüllü olduğuna dair yazılı onam veren öğrencilere formlar araştırmacı tarafından yüz yüze görüşme tekniği kullanılarak uygulanmıştır.

Verilerin değerlendirilmesinde değişkenlerin normal dağılıma uygunluğu Kolmogorov-Smirnov testi ile incelendi. Normal dağılım göstermeyen değişkenler için grup karşılaştırmalarında Mann-Whitney U testi uyguland. Değişkenler arasındaki korelasyon Spearman Korelasyon testi ile incelendi. Kategorik değişkenlerin incelenmesinde Ki-Kare testi ve fisher exact testi uyguland. İstatistiksel anlamlılık $\mathrm{p}<0.05$ olarak kabul edildi.

\section{Bulgular}

Öğrencilerin; \%98.6'sının cinsiyeti kız, \%53.1'i birinci sınıfta, \%51.7'si üniversiteye başlamadan önce il merkezi dışında yaşamakta, \%83.7'si ebelik eğitimine başladıktan sonra mesleğe bakış açılarının olumlu yönde değiştiğini ifade etmektedir. Öğrencilerin \%73.5'i ebelik bölümünü isteyerek seçmiş olup \%55.1'i iş bulma kolaylığı, ekonomik nedenler ve \%32'si istenilen bir meslek olmasından dolayı tercih etmiştir. Öğrencilerin; \%53.7'si mezun olduktan sonra yurt dışında çalışmak istemekte, \%8.8'i konuşma ve anlama düzeyinde yabancı dil bilmekte ve \%76.2'si başka kültürdeki insanlarla bir arada bulunmuştur. Öğrencilerin bildiği yabancı diller İngilizce (\%76.9), Almanca (\%15.4) ve Arapça'dır (\%7,7). Mezun olduktan sonra yurt dışında çalışmak isteyen birinci sınıf öğrencilerinin oranı, dördüncü sınıf öğrencilerinin oranından daha fazla olup aradaki fark istatistiksel yönden anlamlıdır ( $\mathrm{p}<0.05)$, (Tablo 1).

Birinci ve dördüncü sınıf öğrencilerinin kültürlerarası duyarlılık, empati ve merhamet düzeyleri arasında istatistiksel açıdan anlamlı bir farklılık bulunmaktadır ( $\mathrm{p}<0.05)$. Birinci sınıf öğrencilerinin kültürlerarası duyarlılık, merhamet ve bilişsel empati düzeyleri dördüncü sınıf öğrencilerinden daha fazladır $(\mathrm{p}<0.05)$. Merhamet ölçeği alt boyutları açısından; birinci sınıf öğrencilerinin sevecenlik, paylaşımların bilincinde olma ve ilişki kesme düzeyleri, dördüncü sınıf öğrencilerinin ise umursamazlık, bağlantısızlık ve bilinçli farkındalık düzeyleri daha yüksektir ( $<<0.05$ ), (Tablo 2). 
Tablo 1. Öğrencilerin Bazı Sosyo-demografik Özelliklerinin Dă̆ılımı.

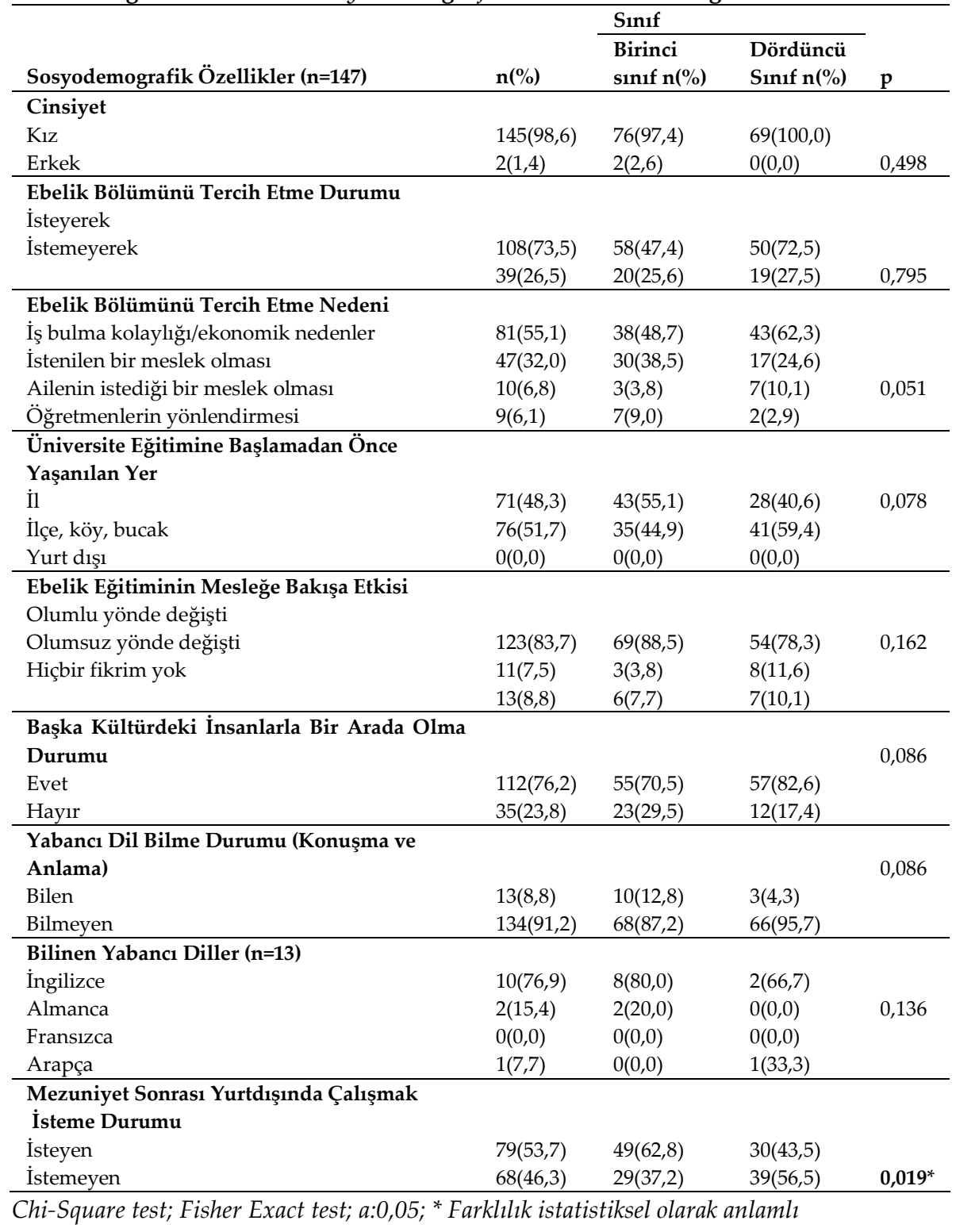


Tablo 2. Öğrencilerin Kültürlerarası Duyarlılık, Temel Empati ve Merhamet Düzeylerinin Dă̆̊lımı (N=147).

\begin{tabular}{|c|c|c|c|}
\hline \multirow[b]{2}{*}{ Ölçek Puan Ortalamaları } & \multicolumn{2}{|l|}{ Sinıf } & \multirow[b]{2}{*}{$\mathrm{p}$} \\
\hline & $\begin{array}{l}\text { Birinci sınıf } \\
\text { Median(Min-Max) }\end{array}$ & $\begin{array}{l}\text { Dördüncü sınıf } \\
\text { Median (Min-Max) }\end{array}$ & \\
\hline \multicolumn{4}{|l|}{ Kültürlerarası Duyarlılık Ölçeği } \\
\hline Toplam & $95,50(41,00-112,00)$ & $85,00(65,00-111,00)$ & $0,001^{*}$ \\
\hline İletişimde Sorumluluk Boyutu & $29,00(7,00-35,00)$ & $26,00(12,00-34,00)$ & $0,001^{*}$ \\
\hline Kültürel Farklılıklara Saygı Boyutu & $25,00(12,00-30,00)$ & $22,00(11,00-30,00)$ & $0,001^{*}$ \\
\hline İletişimde Kendine Güvenme Boyutu & $19,00(7,00-25,00)$ & $17,00(10,00-25,00)$ & $0,023^{*}$ \\
\hline İletişimden Hoşlanma Boyutu & $12,00(4,00-15,00)$ & $11,00(3,00-15,00)$ & $0,001^{*}$ \\
\hline İletişimde Dikkatli Olma Boyutu & $12,00(4,00-15,00)$ & $11,00(6,00-15,00)$ & $0,001^{*}$ \\
\hline \multicolumn{4}{|l|}{ Temel Empati Ölçeği } \\
\hline Toplam & $62,50(51,00-72,00)$ & $62,00(49,00-91,00)$ & 0,598 \\
\hline Duygusal Empati Boyutu & $32,00(21,00-39,00)$ & $31,00(21,00-51,00)$ & 0,485 \\
\hline Bilişsel Empati Boyutu & $31,00(23,00-37,00)$ & $30,00(24,00-40,00)$ & $0,022^{*}$ \\
\hline \multicolumn{4}{|l|}{ Merhamet Ölçeği } \\
\hline Toplam & $83,00(71,00-92,00)$ & $78,00(64,00-88,00)$ & $0,001^{*}$ \\
\hline Sevecenlik Boyutu & $19,00(10,00-20,00)$ & $16,00(9,00-20,00)$ & $0,005^{*}$ \\
\hline Umursamazlık Boyutu & $6,00(4,00-13,00)$ & $8,00(4,00-17,00)$ & $0,004^{*}$ \\
\hline Paylaşımların Bilincinde Olma Boyutu & $17,00(9,00-20,00)$ & $14,00(10,00-20,00)$ & $0,001^{*}$ \\
\hline Bağlantısızlık Boyutu & $6,00(4,00-13,00)$ & $9,00(4,00-18,00)$ & $0,001^{*}$ \\
\hline Bilinçli Farkındalık Boyutu & $6,00(4,00-16,00)$ & $8,00(4,00-16,00)$ & $0,004^{*}$ \\
\hline İlişki Kesme Boyutu & $18,00(10,00-20,00)$ & $16,00(6,00-20,00)$ & $0,002^{*}$ \\
\hline
\end{tabular}

Mann-Whitney U test; a:0,05; * Farklılik istatistiksel olarak anlamlı

Birinci ve dördüncü sınıf öğrencilerinin kültürlerarası duyarlılıkları ile merhamet düzeyleri arasında pozitif yönde, dördüncü sınıf öğrencilerinin kültürlerarası duyarlılıkları ile temel empati düzeyleri arasında negatif yönde anlamlı düzeyde bir ilişki saptanmıştır ( $<<0.05)$, (Tablo 3).

Tablo 3. Öğrencilerin Kültürlerarası Duyarlılık (KDÖ), Temel Empati (TEÖ) ve Merhamet (MÖ) Düzeyleri Arasındaki ilişki (N=147).

\begin{tabular}{|c|c|c|c|c|c|c|c|}
\hline \multirow[b]{2}{*}{ Sinif } & & \multicolumn{2}{|c|}{ Toplam KDÖ } & \multicolumn{2}{|c|}{ Toplam TEÖ } & \multicolumn{2}{|c|}{ Toplam MÖ } \\
\hline & & $\mathrm{r}$ & $\mathrm{p}$ & $\mathrm{r}$ & $\mathrm{p}$ & $\mathrm{r}$ & $\mathrm{p}$ \\
\hline \multirow[t]{3}{*}{ Birinci Sınıf } & Toplam KDÖ & & & & & & \\
\hline & Toplam TEÖ & 0,003 & 0,981 & & & $-0,059$ & 0,606 \\
\hline & Toplam MÖ & 0,262 & $0,021^{*}$ & & & & \\
\hline \multirow{3}{*}{ Dördüncü Sınıf } & Toplam KDÖ & & & & & & \\
\hline & Toplam TEÖ & $-0,337$ & $0,005^{*}$ & & & & \\
\hline & Toplam MÖ & 0,468 & $0,001^{*}$ & $-0,180$ & 0,139 & & \\
\hline
\end{tabular}

Spearman Correlation test;a:0,05; ${ }^{*}$ Farklılı istatistiksel olarak anlaml 


\section{Tartışma}

Küreselleşme, sağlık politikalarının, sağlık hizmet sunumunun, sağlık eğitiminin ve sağlık insan gücünün yeniden gözden geçirilerek yapılandırılmasına olan ihtiyacı ortaya çıarmıştır (Ertaş ve Kıraç, 2017). Sağlık personeli için uluslararası düzeyde istihdam olanağı sağlanmış, sağlık insan gücünde iç ve dış göçler daha cazip hale gelmiştir (Okumuş, Eğin, Kostak ve Çipil, 2016). Ebelerin nitelikli lisans eğitimi ile mesleki bilgi ve becerilerini artırmanın yanında, mesleki vizyonları da olumlu yönde değişmektedir (Atasoy ve Ermin, 2016). Ebelik öğrencilerinin mezuniyet sonrası istihdam planlarına yönelik sınırlı sayıda çalışmaya rastlanmış olup Çalım, Öztürk, Ulaş, Okuyan ve Demirci (2017) dördüncü sınıf ebelik öğrencisi ile yaptığ $\breve{1}$ çalışmada öğrencilerin $\% 45,9^{\prime}$ u mesleğini yurt dışında yapmayı düşündüğünü ifade etmiştir. Çalışmamızda mezuniyet sonrası yurtd1şında çalışmak isteyen öğrencilerin \%62,8'i birinci sınıf, \%43,5'i dördüncü sınıf öğrencisi olup aradaki fark istatistiksel yönden anlamlıdır $(\mathrm{p}<0.05)$. Öğrencilerin eğitime başladıkları ilk yıllarda daha fazla yurtdışında çalışmak istemesi, dördüncü sınıfta bu oranın düşmesi, öğrencilerin lisans eğitimi boyunca zorunlu olarak kültürlerarası ebelik dersi almamalarından ve kendilerini bu alanda yeterli görmemelerinden kaynaklanıyor olabilir.

Kültürlerarası duyarlılık, kültürlerarasındaki farklılıkları görebilmek ve anlayabilmek için gereken öz istekliliktir. Kültürlerarası farklılıkların fark edilmesi ve anlaşılması sağlık bakımının kalitesini artıracaktır. Sağlık bakım alanında kültürlerarası duyarlılığın lisans eğitimi boyunca kazanılması bu nedenle oldukça önemlidir (Bulduk vd. 2011; Valizadeh vd. 2017). Jain (2013) deneysel tipte yaptığı çalışmasında, kültürlerarası duyarlılık eğitimi sonrası, müdahale grubundaki katılımcıların duyarlılığının arttığını belirtmiştir. Ülkemizde yapılan çalışmalarda KDÖ toplam puan ortalaması sağlık çalışanları ve sağlık alanındaki öğrenciler için $78.42 \pm 8.82$ ile 91.28_15.69 arasında değişmektedir (Bulduk vd. 2017; Çetişli vd. 2016; Arli ve Bakan, 2018; Aslan, Yılmaz, Kartal, Erdemir ve Güleç, 2016; Gönenç vd. 2018; Yılmaz, Toksoy, Direk, Bezirgan ve Boylu, 2017; Kılıç ve Sevinç, 2018). Bizim çalışmamızda birinci $(95,50)$ ve dördüncü $(85,00)$ sinıf öğrencilerin KDÖ toplam puan ortalamaları kıyaslandığında, birinci sınıf öğrencilerin puanı anlamlı olarak daha yüksek bulunmuştur $(\mathrm{p}<0.05)$. Çalışmalar bize sağlık çalışanı ve sağlık bilimleri alanındaki öğrencilerin 
kültürel duyarlılıklarının orta ve yüksek düzeyde olduğunu göstermektedir. Kültürlerarası duyarlılığı etkileyen faktörler arasında; farklı kültürlerle etkileşimde bulunma, yabancı dil bilme, farklı kültürle etkileşimi olumlu olarak algılama, büyükşehirde yaşama ve kültür ile ilgili hizmet içi eğitim alma yer almaktadır (Bulduk vd. 2017; Gönenç vd. 2018; Yılmaz vd. 2017; Meydanlioglu, Arikan ve Gozum, 2015). Çalışmamızda dördüncü sınıf öğrencilerinin daha düşük kültürlerarası duyarlılıkta olmasının yabancı dil bilme oranlarının düşük olması ve üniversite öncesi çoğunun il merkezi dışında yaşamış olmalarından kaynaklanabileceği düşünülmektedir.

Empati, kişilerarası iletişimin vazgeçilmez bir bileşenidir ve tüm sağlık personelinin dolayısıyla sağlık alanındaki öğrencilerin kazanması gereken bir beceridir (Aktaş vd. 2016; Chen ve Starosta, 2000; Deane-Gray, 2014). Sağlık alanındaki öğrencilerle yapılan çalışmalarda orta veya yüksek empati düzeyine sahip oldukları bulunmuştur (Cevahir, Çınar, Sözeri, Şahin ve Kuğuoğlu, 2008; Çaka, Topal, Nemut ve Çınar, 2018; Bekmezci, Yurttaş ve Özkan, 2015; Williams vd. 2014). Bilişsel empati bir durum ve olayda kişinin ne hissettiğini anlamak ve farkında olmak iken duygusal empati ise bir durum ve olayda kişi ile aynı şeyleri hissetmek ve kişiye hissettirmektir (Topçu vd. 2010). Çetişli vd. (2016) yaptığ çalışmada birinci $(60.28 \pm 6.25)$ ve dördüncü $(58.98 \pm 5.80)$ sınıf hemşirelik öğrencilerin TEÖ puan ortalamalarını orta düzeyde ve birinci sınıf öğrencilerinin duygusal empati alt boyutunu dördüncü sınıftan yüksek bulmuştur. Benzer şekilde çalışmamızda da birinci $(62,50)$ ve dördüncü $(62,00)$ sınıf ebelik öğrencilerinin TEÖ puan ortalamaları orta düzeyde olup birinci sinıfta okuyan öğrencilerin bilişsel empati alt boyutu puanlarının daha yüksek olduğu saptanmıştır $(p<0.05)$. Yıllar geçtikçe 4 . sınıf öğrencilerinin heyecan ve motivasyonun düşmesi ve farkındalığın azalması, duyarsızlaşma gibi durumlar 1. sınıflara göre TEÖ alt boyutundan alınan düşük puanları açıklayabilir.

Merhamet sağlık bakım sunucularında olması gereken önemli bir değer olup merhamet duyularak bireylere sunulacak bakımın temeli lisans eğitimi sırasında kazanılmalıdır (Bray, O'Brien, Kirton, Zubairu ve Christiansen, 2014; Çingöl, Çelebi, Zengin ve Karakaş, 2018). Ebelerin bağımsız rollerinden biri olan destekleyici ebelik bakımının odağında merhamet oldukça önemlidir (Şimşek, Demirci ve Bolsoy, 2018). Merhamete dayalı 
ebelik bakımı ile ana-çocuk sağlığı yükseltilir ve travmalara karşı koruyuculuk sağlanır (Knapp, 2015). Sağlık bakım uygulayıcılarının (personel, öğrenci) merhamet düzeylerini belirlemeye yönelik sınırlı sayıda çalışmaya rastlanmış olup merhamet düzeylerinin yüksek olduğu bulunmuştur (Arli ve Bakan, 2018; Çingöl vd. 2018; Shih vd. 2017). Çalışmamızda birinci sinıf öğrencilerinin merhamet düzeyleri dördüncü sinıf öğrencilerinden daha fazladır $(\mathrm{p}<0.05)$. Merhamet ölçeği alt boyutları açısından; birinci sınıf öğrencilerinin sevecenlik, paylaşımların bilincinde olma ve ilişki kesme düzeyleri, dördüncü sınıf öğrencilerinin ise umursamazlık, bağlantısızlık ve bilinçli farkındalık düzeyleri daha yüksektir ( $\mathrm{p}<0.05)$. Sınıflar arasındaki bu farklılık eğitim sırasında merhamet eğitiminin olmamasından kaynaklanabilir. Tıp öğrencileriyle yapılan bir çalışmada, merhamet odaklı eğitimin, öğrencilerin merhametli bakım algılarını artırdığı rapor edilmiştir (Shih vd. 2017).

Kültürlerarası duyarlılığa sahip olunması merhamet ve empatik yaklaşımın yükselmesine, merhamet ve empatik yaklaşım kültürlerarası duyarlılığın artmasına neden olabilmektedir (Ménage vd. 2017). Öğrencilerin kültürlerarası duyarlılık, empati ve merhamet düzeylerinin birbiri ile olan ilişkisini inceleyen yurtiçi ve yurt dışı çalışmaya rastlanmamıştır. Bir çalışmada, hemşirelerin kültürlerarası duyarlılıkları ile merhamet düzeyleri arasında pozitif yönde ilişkiye rastlanmıştır (Arli ve Bakan, 2018). Bizim çalışmamızda birinci ve dördüncü sınıf öğrencilerinin kültürlerarası duyarlılıkları ile merhamet düzeyleri arasında pozitif yönde, dördüncü sınıf öğrencilerinin kültürlerarası duyarlılıkları ile temel empati düzeyleri arasında negatif yönde anlamlı düzeyde bir ilişki saptanmıştır $(\mathrm{p}<0.05)$. Eczacılık birinci sınıf öğrencilerle yapılan bir çalışmada öğrencilerin kültürlerarası duyarlılık ve empati eğitimlerine ihtiyaçları olduğu belirlenmiştir (Ekong, Kavookjian ve Hutchison, 2017).

\section{Sonuç}

Sonuç olarak birinci ve dördüncü sınıf öğrencilerinin kültürlerarası duyarlılıkları arttıkça merhamet düzeyleri artmakta iken dördüncü sınıf öğrencilerinin kültürlerarası duyarlılıkları arttıkça temel empati düzeyleri azalmaktadır. Elde edilen bulgular doğrultusunda; ebelik öğrencilerinin kültürlerarası yaklaşımlarının merhamet düzeyleri üzerine olumlu etkisi 
Ebelik Öğrencilerinin Kültürlerarası Yaklaşımlarının Merhamet ve Empati Düzeylerine Etkisi

olduğu sonucuna varılabilir. Bu sonuçlara yönelik öğrencilerin; kültürel bakış açılarının ve farkındalıklarının arttırılması için kültürel duyarlılık, farkındalık eğitimlerin düzenlenmesi ve eğitim programlarında bu konuya yer verilmesi, farklı örneklem gruplarında kültürlerarası duyarlılık, merhamet ve temel empati ilişkisinin araştırılması önerilmektedir. 


\title{
EXTENDED ABSTRACT
}

\section{The Effect of Intercultural Approaches of Midwifery Students on the Level of Compassion and Empathy}

\author{
Gülbahtiyar Demirel - Nurdan Kaya - Adem Doğaner \\ Sivas Cumhuriyet University, Kahramanmaraş Sütçü İmam University
}

In a changing world, the concepts of cultural awareness and sensiti-vity have emerged in health care services and their importance in care provision has begun to be emphasized. Empathy is one of the central elements of intercultural sensitivity. Compassion is an important value for health care providers. Midwifery is one of the professions that carry an important role and responsibility in the provision of health care services. Intercultural sensitivity of midwifery students who will be midwives of the future may affect compassion, empathic approach and the quality of care. In this respect, it is important to determine the intercultural approaches of midwifery students. In the literature, there is no study investigating how intercultural approaches of midwifery students affect empathy and compassion. Therefore, this study was conducted to determine the effect of intercultural approaches of midwifery students' on their empathy and compassion levels.

This descriptive study was conducted in the Department of Midwifery, Faculty of Health Sciences, Cumhuriyet University, Sivas. The population of the study consisted of first (85 people) and fourth (73 people) grade midwifery students studying in Sivas Cumhuriyet University Faculty of Health Sciences Department of Midwifery in 2017-2018 academic year. The sample of the study consisted of first (78 people) and fourth (69 people) grade midwifery students who studied in the spring semester of 2017-2018 academic year and volunteered to participate in the study. The data of the study were collected by "Student Presentation Form" which was prepared by the researchers in line with the literature, "Intercultural Sensitivity Scale", "Basic Empathy Scale" and "Self-Compassion Scale".

Before the research, written permission was obtained from Sivas Cumhuriyet University Faculty of Health Sciences and Sivas Cumhuriyet 
University Non-Interventional Clinical Research Ethics Board (201801/27). The students who volunteered to participate in the study were informed about the purpose and content of the study and their written consent was obtained for their participation. In order to obtain the data correctly, it was stated that it was not obligatory to specify a name in the other data collection form except the consent form and that all information would remain confidential. It was also stated that the data would be used only within the scope of the research and confidentiality would be ensured. The forms were applied to the students who gave written consent that they were willing to participate in the research by face to face interview technique.

In the evaluation of the data, Kolmogorov-Smirnov test was used to identify the appropriateness of the variables to normal distribution. Mann-Whitney U test was used for group comparisons for variables that did not show normal distribution. The correlation between the variables was examined by Spearman Correlation test. Chi-square test and fisher exact test were used to examine categorical variables. Statistical significance was accepted as $\mathrm{p}<0.05$.

According to the data obtained from the study, $98.6 \%$ of the students were female, $53.1 \%$ were in the first grade, $51.7 \%$ lived outside the city center before starting university, $83.7 \%$ stated that their attitudes towards the profession changed positively after starting midwifery education. $73.5 \%$ of the students chose the midwifery department willingly and $55.1 \%$ preferred it because of the ease of finding a job and economic reasons, and $32 \%$ preferred because of its being a desired profession. $53.7 \%$ of the students wanted to work abroad after graduation, $8.8 \%$ knew a foreign language at the level of speech and comprehension, and $76.2 \%$ spent time together with people from other cultures. The foreign languages spoken by the students were English (76.9\%), German (15.4\%) and Arabic $(7.7 \%)$. The rate of first grade students who wanted to work abroad after graduation was higher than that of fourth grade students and the difference between them was statistically significant $(\mathrm{p}<0.05)$.

There was a statistically significant difference among the intercultural sensitivity, empathy and compassion levels of the first and fourth grade students $(p<0.05)$. Intercultural sensitivity, compassion and cognitive empathy levels of first grade students were higher than fourth grade students 
$(\mathrm{p}<0.05)$. In terms of compassion scale subscales, first grade students had higher levels of affection, awareness of sharing and disconnection, and fourth grade students had higher levels of indifference, disconnection and conscious awareness $(\mathrm{p}<0.05)$. A significant correlation was found between the intercultural sensitivity and compassion levels of the first and fourth grade students, and a negative correlation was found between the intercultural sensitivity and basic empathy levels of the fourth grade students $(\mathrm{p}<0.05)$.

As a result, as the intercultural sensitivity of first and fourth grade students increased, their compassion levels increased, while the intercultural sensitivity of fourth grade students increased, their basic empathy levels decreased. Accordingly, it can be concluded that intercultural app-roaches of midwifery students have a positive effect on their compassion levels. In line with these results, it is recommended that cultural sensitivity, awareness trainings should be organized in order to increase students' cultural perspectives and awareness, these issues should take place in education programs, the relationship among cultural awareness, compassion and basic empathy should be investigated in different samp-le groups.

\section{Kaynakça / References}

Akdeniz, S. ve Deniz, M.E. (2016). Merhamet ölçeği'nin Türkçe'ye uyarlanması: Geçerlik ve güvenirlik çalışması. The Journal of Happiness $\mathcal{E}$ WellBeing, 4(1), 50-61.

Aktaş, Y.Y., Uğur, H.G. ve Orak, O.S. (2016). Hemşirelerin kültürlerarası hemşirelik bakımına ilişkin görüşlerinin incelenmesi. Uluslararası Hakemli Hemşirelik Araştırmaları Dergisi, 8, 120-135.

Arli, S.K. ve Bakan, A.B. (2018). An investigation of the relationship between intercultural sensitivity and compassion in nurses. International Journal of Intercultural Relations, 63, 38-42.

Aslan, S., Yılmaz, D., Kartal, M., Erdemir, F. ve Güleç, H.Y. (2016). Determination of intercultural sensitivity of nursing students in Turkey. Int J Health Sci Res, 6(11), 202-208.

Atasoy, I. ve Ermin, C. (2016). Hemşirelik ve ebelik öğrencilerinin mesleklerine bakış açısının incelenmesi. Düzce Üniversitesi Sağllk Bilimleri Enstitüsü Dergisi, 6(2), 83-91. 
Bekmezci, H., Yurttaş, Ç.B. ve Özkan, H. (2015). Ebelik bölümü öğrencilerinin empatik eğilim düzeylerinin belirlenmesi. HSP , 2(1), 46-54.

Bray, L.O.M.R., Kirton, J., Zubairu, K. ve Christiansen, A. (2014). The role of professional education in developing compassionate practitioners: A mixed methods study exploring the perceptions of health professionals and pre-registration students. Nurse Education Today, 34, 480-486. doi:10.1016/j.nedt.2013.06.017.

Bulduk, S., Tosun A. ve Ardıç, E. (2011). Türkçe kültürlerarası duyarlılık ölçeğinin hemşirelik öğrencilerinde ölçümsel özellikleri. Turkiye Klinikleri Journal of Medical Ethics, 19(1), 25-31.

Bulduk, S., Usta, E. ve Dinçer, Y. (2017). Kültürlerarası duyarlılık ve etkileyen faktörlerin belirlenmesi: Bir sağlık hizmetleri meslek yüksekokulu örneği. Düzce Üniversitesi Sağlık Bilimleri Enstitüsü Dergisi, 7(2), 73-77.

Cetişli, N.E., Işık, G., Öztornacı, B.Ö., Ardahan, E., Uran, B.N.Ö., Top, E.D. ve Avdal, E.Ü. (2016). Hemşirelik öğrencilerinin empati düzeylerine göre kültürlerarası duyarlılıkları. İzmir Kâtip Çelebi Üniversitesi Să̆lık Bilimleri Fakültesi Dergisi, 1(1), 27-33.

Cevahir, R., Çınar, N., Sözeri, C., Şahin, S. ve Kuğuoğlu, S. (2008). Ebelik öğrencilerinin devam ettikleri sinıflara göre empatik becerilerinin değerlendirilmesi. Fırat Sağlık Hizmetleri Dergisi, 3(7), 3-15.

Ceylantekin, Y. ve Öcalan, D. (2016). Hemşirelik öğrencilerinin kültürel farkındalığı ve kültürlerarası hemşirelik dersine yönelik düşünceleri. GÜSBD, 5(4), 45-53.

Chen, G.M. ve Starosta, W. (2000). The development and validation of the Intercultural Sensitivity Scale. Human Communication, 3(1), 2-14.

Çaka, S.Y., Topal, S., Nemut, T. ve Çınar, N. (2018). Hemşirelik ve ebelik öğrencilerinde aleksitimi ile empati arasındaki ilişki. Journal of Human Sciences, 15(2), 996-1005.

Çalım, S.İ., Öztürk, E., Ulaş, S.C., Okuyan, Y.Ç. ve Demirci, H. (2017). Ebelik 4. sınıf öğrencilerinin mesleği seçme nedenleri ve mezuniyet sonrası istihdam planları. MCBU-SBED, 4(4), 1039-1042.

Çingöl, N., Çelebi, E., Zengin, S. ve Karakaş, M. (2018). Bir sağlık yüksekokulu hemşirelik bölümü öğrencilerinin merhamet düzeylerinin incelenmesi. Klinik Psikiyatri, 21, 61-67.

Deane-Gray, T. (2014). Effective communication: The student's guide to becoming a midwife. Second Edition, (Ed. I. Peate and C. Hamilton), Hoboken: John Wiley \& Sons. 
Dinç, L. (2010). Bakım kavramı ve ahlaki boyutu. Hacettepe Üniversitesi Să̆lık Bilimleri Fakültesi Hemşirelik Dergisi, 17(2), 74-82.

Ekong, G., Kavookjian, J. ve Hutchison, A. (2017). Predisposition for empathy, intercultural sensitivity, and intentions for using motivational interviewing in first year pharmacy students. American Journal of Pharmaceutical Education, 81(8), 59-89.

Ertaş, H. ve Kıraç, F.Ç. (2017). Küreselleşmenin ülkelerin sağlık sistemleri ve politikaları üzerine etkileri. Kastamonu Üniversitesi İktisadi ve İdari Bilimler Fakültesi Dergisi, 17(3), 28-34.

Gönenç, İ.M., Göktaş, M., Dursun, A.R., Çökelek, F., Ercan, N. ve Şahin, D. (2018). Opinions and cultural sensitivities of midwives and nurses about providing health care to women seeking asylum. Journal of $\mathrm{Hu}$ man Sciences, 15(2), 683-696.

Jain, S. (2013). Experiential training for enhancing intercultural sensitivity. J Cult Divers Spring, 20(1), 15-20.

Jolliffe, D. ve Farrington, D.P. (2006). Development and validation of the Basic Empathy Scale. Journal of Adolescence, 29, 589-611.

Kılıç, S.P. ve Sevinç, S. (2018). The relationship between cultural sensitivity and assertiveness in nursing students from Turkey. J Transcult Nurs, 29(4), 379-386. doi: 10.1177/1043659617716518.

Knapp, R. (2015). Where there was love ... Compassionate midwifery as protection against trauma. Pract Midwife, 18(3), 17-19.

Ménage, D., Bailey, E., Lees, S. ve Coad, J. (2017). A concept analysis of compassionate midwifery. J Adv Nurs, 73(3), 558-573.

Meydanlioglu, A., Arikan, F. ve Gozum, S. (2015). Cultural sensitivity levels of university students receiving education in health disciplines. Adv Health Sci Educ Theory Pract, 20(5), 1195-1204. doi: 10.1007/s10459-0159595-z.

Okumuş, N., Eğin, E., Kosdak, M. ve Çipil, Z. (2016). Sağlık çalışanlarının uluslararası göçü/istihdamı. Ankara: T.C. Sağlık Bakanlığı Sağlık Hizmetleri Genel Müdürlüğü Sağlık İnsan Gücü Planlama Daire Başkanlığı.

Polat, F.N. ve Erdem, R. (2017). Merhamet yorgunluğu düzeyinin çalışma yaşam kalitesi ile ilişkisi: Sağlık profesyonelleri örneği. Süleyman Demirel Üniversitesi Sosyal Bilimler Enstitüsü Dergisi, 26(1), 291-312.

Pommier, E.A. (2011). The Compassion scale. Humanities and Social Sciences, 72,1174 . 
Shih, C.Y., Hu, W.Y., Lee, L.T., Yao, C.A., Chen, C.Y. ve Chiu, T.Y. (2017). Effect of a compassion-focused training program in palliative care education for medical students. American Journal of Hospice \& Palliative Medicine, 30(2), 114-120. doi:10.1177/1049909112445463

Şimşek, H.N., Demirci, H. ve Bolsoy, N. (2018). Sosyal destek sistemleri ve ebelik. Düzce Üniversitesi Să̆lık Bilimleri Enstitüsü Dergisi, 8(2), 97-103.

Tanrıverdi, G. (2017). Hemşirelerde kültürel yeterliliği geliştirmeye yönelik yaklaşım ve öneriler. FNJN Florence Nightingale Hemşirelik Dergisi, 25(3), 227-236.

Topçu, Ç., Baker, E.Ö. ve Aydın Ç.Y. (2010). Temel Empati Ölçeği Türkçe uyarlaması: Geçerlik ve güvenirlik çalışması. Türk Psikolojik Danışma ve Rehberlik Dergisi, 4(34), 174-182.

Tortumluoğlu, G. (2004). Transkültürel hemşirelik ve kültürel bakım modeli örnekleri. C.Ü. Hemşirelik Yüksekokulu Dergisi, 8(2), 47-57.

Uslu, E. ve Buldukoğlu, K. (2017). Psikiyatri hemşireliğinde şefkat yorgunluğu: Sistematik derleme. Psikiyatride Güncel Yaklaşımlar, 9(4), 421-430.

Valizadeh, L., Zamanzadeh, V., Ghahramanian, A. ve Aghajari, P. (2017). The exploration of culturally sensitive nursing care in pediatric setting: A qualitative study. Int J Pediatr, 5, 4329-4341.

Williams, B., Brown, T., Boyle, M., McKenna, L., Palermo, C. ve Etherington, J. (2014). Levels of empathy in undergraduate emergency health, nursing, and midwifery students: A longitudinal study. Advances in Medical Education and Practice, 5, 299-306. http://doi.org/10.2147/AMEP.S66681

Yılmaz, M., Toksoy, S., Direk, Z.D., Bezirgan, S. ve Boylu, M. (2017). Cultural sensitivity among clinical nurses: A descriptive study. J Nurs Scholarsh, 49(2), 153-161. doi:10.1111/jnu.12276

\section{Kaynakça Bilgisi / Citation Information}

Demirel, G., Kaya, N. ve Doğaner, A. (2020). Ebelik öğrencilerinin kültürlerarası yaklaşımlarının merhamet ve empati düzeylerine etkisi. OPUS-Uluslararası Toplum Araştırmaları Dergisi , 15(21), 282300. DOI: 10.26466-/opus.591200 